\title{
LA CABEZA Y LA MANO, NOTAS SOBRE UNA LENGUA Y UNA MORAL: LAS SIENES DEL ASNO DE ORO, DE ALEJANDRO GODOY ${ }^{1}$
}

\author{
Javier Bello \\ Universidad de Chile \\ jbello@gmail.com
}

Cabeza y mano ejercen en la escritura de Alejandro Godoy -y digo escritura y no poemas, porque este libro me parece una continuidad de fragmentos y no una serie de textos cerrados como una colección o álbum lírico- la búsqueda ambigua, variable, en fugas y regresos a lo largo de una espiral, de un cuerpo sacrificial que pueda sostenerlas y -apurado por la cita del siempre joven Arthur Rimbaud: "La moral y la lengua están reducidas, por fin, a su expresión más simple” (Godoy 2012: 5)- una moral y una lengua en las que el poeta quiere, debe y quizá pueda participar, pero que constantemente lo expulsan y lo identifican, circunscribiéndolo a aquel "prestigioso" lugar de marginalidad en que la poesía latinoamericana, desde el modernismo, ha relegado la figura del poeta: por un lado, fiel testigo de aquello que no le pertenece ya de ningún modo, de lo que fue separado por un corte doloroso y abrupto, insistente portador de un legítimo reclamo de pertenencia, y por otro lado, a la vez, liberado artífice de los deberes y de los roles atribuidos, y crítico implacable de lo que lo constituye por propia definición a partir del distanciamiento que implicó ese despojo. Teniendo en cuenta lo anterior, aventuro

1 No haré referencias en esta nota a la relación que establece el título de Godoy con $E l$ asno de oro o Las metamorfosis de Lucio Apuleyo, por no representar una intertextualidad directa con respecto a los contenidos y figuras de la novela romana. La poética de Godoy no aborda las formas narrativas de lo que en Apuleyo se ha llamado un adelanto de la muy posterior novela picaresca, ni tampoco de la representación de la vida miserable de las clases bajas que realiza el autor a partir de la transformación del personaje principal, el noble Lucio, en burro, fruto de un error en la práctica de la magia, interés que mueve al personaje en su búsqueda. Lo que podría, de manera indirecta, relacionarse con la obra de Apuleyo es la capacidad transformativa del sujeto de Godoy, lo que resulta bastante general. Tampoco con el tipo de representación de lo sexual, que en la obra latina se produce de manera explícita y hasta graciosa. Tanto la índole como el tono de ambos textos son sustancialmente distintos. 
entonces una primera cuestión que sería necesario abordar alrededor de los textos de Godoy: ¿están reducidas la moral y la lengua a su expresión más simple en estas páginas?, ¿qué significa elaborar y enarbolar una lengua en estos poemas?, ¿qué moral es la que circula entre las sienes del asno de oro? ¿Queda reducido el dolor en estos poemas? ¿el pathos?, son cuestionamientos que de igual manera se podrían también añadir.

Recuerdo una sentencia de Epicuro que afirma que el mito religioso amarga la vida de los hombres, pero he aquí que desde Gabriela Mistral, Vicente Huidobro, Winétt y Pablo De Rokha, Rosamel del Valle, Humberto Díaz-Casanueva, hasta Raúl Zurita, Soledad Fariña y aún más acá -David Preiss, Alejandra del Río, Jaime Huenún, Antonia Torres, solo por nombrar a algunos autores más cercanos temporalmente al libro de Godoy- el mito religioso, su devenir profético y las disputas que lo sustentan, resulta una sustancia -quizá la sustancia- fundacional en el territorio de nuestra lírica. Esa amargura que es parte del pathos que afecta estos poemas aparentemente-isolo aparentemente?--dorados, recubiertos por una lengua y una moral particulares, desazón que al mismo tiempo, quizá perversamente pero también, al mismo tiempo, de manera aurática o sublime, le permite al poeta, más allá o más acá del goce de la escritura, deleitarse en la propia monstruosidad y delito de su insistencia en el lenguaje.

Lo primero que veo aparecer es una cabeza: sienes, ceño, párpado, retina, labio, boca, rostro, encía, dientes, ceja, nuca, guedeja, cráneo. ¿Una cabeza agonizante? ¿de asno? ¿de oro? ¿cortada? ¿despedazada? ¿aborrecida? (¿Por qué se me viene a la cabeza la palabra aborrecida?). Una cabeza que más allá de su efecto simbólico se entrega como una representación carnal que cunde e incluso redunda en sus partes y fluidos, aunque descompuesta, desorganizada, como una "pasta", palabra que, aproximada aquí a la noción de "mezcla" girondiana ${ }^{2}$, podría ser el comienzo de la elaboración de una poética, la poética en que se adentra el autor a partir de este libro, haciéndose cargo de manera absoluta y encarnizada de aquella entidad de carácter orgánico y libidinal, que supone a su vez un campo de fuerzas desconocidas, discontinuas y contradictorias, en la que parece luchar, debatirse, descomponerse, junto a la cual parece despeñarse al mismo tiempo que extenderse y a veces ascender. Una cabeza que no es tampoco el espacio que no ha tenido representación, como en el poemario de Andrés Anwandter, titulado Especies intencionales (Anwandter 2001), lugar del reflejo y del eco, de la ausencia significante del autor ${ }^{3}$, sino, como decía, más allá de lo simbólico y sus límites,

2 "La mezcla" (Girondo 1999: 219) es el texto inicial de En la masmédula, el último poemario de Oliverio Girondo, y que parece aludir a los poderes constructivos/destructivos del lenguaje en el trasfondo indefinido y proteico que titula al libro mediante esa metáfora referente a la albañilería: "la mezcla con que adherí mis puentes" dice el último verso. De ahí la posible asociación con la "pasta" que parece constituir la corporalidad cambiante y mortificada del sujeto que parece "construirse" y "destruirse" a lo largo de estos poemas de Godoy.

Breve y magistral ejemplo de lo anterior podemos encontrar en el volumen recién citado de Andrés Anwandter, en el poema "Cráneo": "Si comienzo a caminar por ese espacio cuya forma/ es la forma de un espacio que recuerdo y no conozco/ o conozco y no recuerdo:/ 
y más allá de la investigación concreta de las lindes de lo (i)rrepresentable, un pasadizo hacia el imposible del cuerpo, una "cabeza roída por dentro" cubierta por una "corteza gangrenada" (Godoy 2012: 9), no un (in)habitable espacio craneal y cerebral sino la agonía que se deja caer sobre otro, el peso carnal y espiritual del pathos que reclama un lugar entre los otros, entre nosotros.

Se trata del peso del cuerpo de Cristo, del sacrificado, que de manera explícita a partir del quinto poema del libro (Godoy 2012: 15), -si no tácitamente desde antesse identifica con el sujeto hablante, suplicante, que pide: "Ahora, Madre, bájame los párpados", una inversión radical del comienzo del aquí recurrente poema "Éxtasis" de Mistral: "Ahora, Cristo, bájame los párpados", escribe la poeta en su apóstrofe a la Madre-Cristo (Mistral 1958: 64-5). La herejía mistraliana reiterada en Desolación y de manera residual en Tala-solicitar la muerte más allá del designio divino ${ }^{4}$ - se transforma en una petición espejeante del sujeto a esta misma Madre-Cristo identificada aquí con Mistral -atendiendo perspicazmente a la fusión de la sujeto con esta figura presente en los propios textos de la autora-, asociada también en otros momentos del libro de Godoy al árbol -sobre todo el roble-, el elemento restante de la trilogía elaborada por Patricio Marchant (Marchant 1984, 2000) como núcleo interpretativo de la poesía de la autora chilena. "Ahora, Madre, bájame los párpados", escribe el poeta, para develar estos pliegues y repliegues literarios que lo atañen y circundan, que lo hacen y deshacen, lo ocultan y lo exhiben, y lo contaminan.

Así, a partir de este gesto, Godoy elabora una cabeza vuelta hacia dentro, cerrada, muerta-viva, con los párpados abajo, lo que le permite también ocluir el poema, emanciparlo de la referencia, hacer de la confesión de su despojo un botín de palabras, un amotinamiento en la lengua, un ejercicio barroco luctuoso que así como se goza en la muerte lo hace en la agramaticalidad y la asignificación, la anasemia y la afasia, torsiones (in)debidas en el lenguaje comunicacional y en el confesionalismo del relato, abuso de pobreza del panorama generacional que rodea al autor, lo diferencia y destaca radicalmente, lo que resulta en la poesía chilena de estas últimas dos décadas, al menos, una seductora provocación. Este suceso en el lenguaje, este logro de la poesía de Godoy, manifiesta en el volumen varias referencias directas e indirectas que no pretendo agotar en este breve recuento: esta ocurrencia en Las sienes del asno de oro encuentra paralelo en la poesía de José Lezama Lima -“padre Lezama” (¡sic!), lo llama en uno de los poemas del volumen (Godoy 2012: 39)-, como también, por ejemplo, en la de Néstor Perlongher y, de manera menos evidente pero no menos rotunda, en el Canto VI de

en esos casos, el eco -en esos casos, espantoso- de mis pasos me despierta/ todavía ante la puerta de esa forma: abierta" (Anwandter 2001: 21).

Me refiero al "Nocturno" de Desolación (Mistral 1958: 79-80) y al "Nocturno de la consumación" de Tala (Mistral 1958: 382-4), a los que se podría agregar "El ruego" de Desolación (Mistral 1958: 99-101), donde la hablante pide a Dios Padre perdón para el amante suicida. 
Altazor de Vicente Huidobro 5 , lo que resulta especialmente notable en la manufactura del texto y en la elaboración de una poética de lo abierto y lo cerrado, esa interfaz del límite en Altazor, la alegoría reductora de la bisagra universal en el tropo del "nudo", del "molusco" y la trizadura de la joya parnasiana, parecida al febril trabajo del poeta con esa cabeza muerta, putrefacta, cuyas sienes Godoy dora en su dramática filigrana craneal, en el lacado de bijouterie de un órgano y un cuerpo que se autodestruye cuando "las costillas se hienden a sí mismas" (Godoy 2012: 25), cada vez que el material de su obsesión, el de las palabras, cede y éstas lo abandonan.

No sería difícil, al calificar los modos de apropiación de la familia poética que articula el libro de Godoy, hablar de paraíso artificial, de simulacro, de copia con y sin original, y resultaría productivo hacerlo siempre y cuando tengamos presente que detrás de estos pletóricos parentescos se agita un peso muerto, yace un cadáver que se entrega, una cabeza que cae para ser recogida, y que en estas páginas apuntala cualquier filiación y estrategia literaria. La herejía de Godoy parece constituirse a partir de, dentro de, en contra de, más allá y más acá de la poesía chilena, sí, pero en tanto ésta puede entenderse como una lengua y una moral que ante el mito, la divinidad y la historia definen una forma de producción simbólica que ha encarnado, con diversas intensidades, en las formas particulares de poetizar. Nuestra moral y nuestra lengua -o lo que queda de ellas-, de las que el poeta se muestra devoto, a la vez que manteniéndose en una posición de marginalidad, como intenté adelantar en las primeras líneas de este trabajo.

A partir de sus exploraciones y calados en la cabeza, el poeta se pasa al trabajo negativo de unos dedos masturbatorios y anales: "Moliendo el pulso se deshoja en mis dedos el musgo afelpando su tajada" (Godoy 2012: 9). Hay algo violento, un daño, que se esconde en el uso gozoso de las palabras de Las sienes del asno de oro. El ejercicio gongorino y lezamiano de la lengua es intervenido por este escarbar, deshojar, romper del poeta, ese tajo neobarroco, en el que también goza. Su recorrido por el mito lo lleva de la cabeza de la Madre a la mano del Padre: "la mano de Dios que escribe tan antigua como el hambre me ha dejado ciego" (Godoy 2012: 11). Se trata de la mano que engendra simbólicamente mediante el lenguaje y la letra, la mano que crea a su imagen y semejanza, que constituye e impone con dolor, y ante la que el sujeto elaborará diversas y desvariantes formas de desviación. Su marginalidad se articula frente a esta figura poderosa a partir del relato de un oprobioso y cruel despojo: es esa mano la que lo deja ciego, haciéndolo ingresar, de golpe y porrazo, en el paradigma profético, como un Tiresias y como un

5 Cito algunos fragmentos del "Canto VI" de Altazor (Huidobro 2003: 802-3): "Alhaja apoteosis y molusco/ Anudado/ noche/ nudo/ El corazón/ Esa entonces dirección/ nudo temblando/ Flexible corazón la apoteosis/ Un dos tres/ cuatro/ Lágrima/ mi lámpara/ y molusco/ El pecho al melodioso/ Anudado la joya/ Conque temblando angustia/ Normal tedio/ Sería pasión/ Muerte al violoncelo/ Una bujía el ojo/ Otro otra/ Cristal si cristal era/ Cristaleza/ Magnetismo/ sabéis la seda/ Viento flor/ lento nube lento/ Seda cristal lento seda/ El magnetismo/ seda aliento cristal seda/Así viajando en postura de ondulación/ Cristal nube/ Molusco sí por violoncelo y joya/ Muerte de joya y violoncelo/ Así sed por hambre y hambre y sed/ Y nube y joya”. 
Jeremías, despojado de visión y masculinidad. Más aún -y esto resulta clave a la hora de situar la herejía de este sujeto frente al mito fundante del monoteísmo-, la creación parece haberse ausentado en él, habiéndose retrasado. Creado a partir de una imagen que se tarda en llegar, que lo desdobla y lo invierte en una desemejanza fundamental con respecto al Padre (Godoy 2012: 11, 31), él es alguien que por el carácter desajustado, incierto y ambiguo de su propia constitución, está condenado a construir su humanidad fuera de los territorios y las formas normadas.Y este saber, adquirido a partir del reñido enfrentamiento del poeta y su numen con estas entidades tutelares, resulta el aprendizaje mayor que estos textos proponen a partir de su búsqueda en esa conmocionada interfaz que suponen los deseos personales y la cultura.

La emulación negativa, demónica, de la creación divina paterna, y la emulación positiva, sumisa, de la misma, y todos los estados intermedios de negociación -cuyo filtro no es otro que el propio sujeto: "dios albergado en mi boca" (Godoy 2012: 11)termina por construir la figura - una ilusión compensatoria de la ausencia- de un Dios Padre que cede en su quehacer, que no es capaz de responder, conceder o castigar (el poema "El Dios triste", de Mistral, resulta aquí otra referencia productiva ${ }^{6}$ ); asistimos así a la vejez de la mano, cubierta de musgo, que se rinde, se entrega, ¿en pos de quién sino de la voz (des)autorizada del propio sujeto? Alrededor de la polaridad lealtad y traición (Godoy 2012: 13) se instala la cuestión de la obediencia al padre, al Creador, por parte de la mano que intenta escribir lo suyo: lo propio y lo ajeno. Pertenencia, identidad, emulación, pero también desidentificación, disputa, exilio. Basta con revisar otro par de tópicos mistralianos aquí esbozados: "el padecimiento de la doble patria" (Godoy 2012: 37) y el antisalmo de Godoy a partir del modélico "Salmo 23", "Adonay mi pastor, no desfaleceré” (Tehilim, 23. Biblia de Ferrara 2004: 936-7), conversión del poema "Aguas"7, de Tala: el sujeto es traído, esta vez por la Madre Mistral, a "país sin río" (Godoy 2012 : 9).

Hay en estos poemas otra figura, quizá un poco más cotidiana y cercana, la cual, retrospectivamente con respecto a la línea de descendencia, parece mediar la lejana y terrible solemnidad del Padre; ésta resulta, finalmente, una mediación simulada, a su vez también devastadora, una distención que vuelve a tensarse sobre el sujeto. Se trata del

$6 \quad$ "El Dios triste" es uno de los poemas de Desolación que en los primeros dos libros de Gabriela Mistral describe una particular sustitución de divinidades que, a mi entender, culmina en los poemas "Nocturno del Descendimiento" y "Locas letanías" de Tala, donde la sujeto recupera el cuerpo vivo de Cristo después de la Crucifixión y presencia la salvación de la madre muerta; en "El Dios triste" la sujeto se enfrenta a un Dios Padre débil, enfermo, herido, decadente, "un Dios de otoño, un Dios sin ardor y sin canto./ ¡Y lo conozco triste, lleno de desaliento!//Y pienso que tal vez Aquel tremendo y fuerte/ Señor, al que cantara de locura embriagada,/ no existe, y que mi Padre que las mañanas vierte/ tiene la mano laxa, la mejilla cansada" (Mistral 1958: 37-8).

En la segunda estrofa de "Aguas", Mistral escribe: "Me han traído a país sin río,/ tierras-Agar, tierras sin agua;/ Saras blancas y Saras rojas,/ donde pecaron otras razas" (Mistral 1958: 447). 
Abuelo, una presencia mágica y arcaica, cercana a lo vegetal y a lo animal, que recubre al sujeto de hebras, enfrascado éste último en la total cerrazón del dédalo; el abuelo del tejido o las barbas, relacionado con el tronco arcaico del árbol de las familias, el tótem hirsuto y el linaje masculino, de los que el sujeto no puede participar: "Mi abuelo miraba con orgullo a sus nietos varones" (Godoy 2012: 35). A diferencia de ellos, aquel que fue besado por "un hombre desposado con la hambruna", habló "a dioses sin volumen o peso" (Godoy 2012: 19), dioses que no son el tronco del Árbol Cristo, frente a éste simples ídolos, cáscaras vacías, inexistentes o intrascendentes como sucede en "El Dios triste" de Mistral, dioses que, como dice Marchant siguiendo a Heidegger, no pueden dar forma a un modo particular, colectivo, de existencia ${ }^{8}$.

Aquel que es llamado mujer (Godoy 2012: 35) -como en el libro del profeta Jeremías: si Israel es la esposa infiel y la prostituta (Yrmeahu 3, Biblia de Ferrara 2004: 701-2), el profeta es feminizado, seducido y forzado por el Padre, en su fidelidad a Adonai (Yrmeahu 20, 7, Biblia de Ferrara 2004: 727)- declara: "no soy hombre como ustedes" (Godoy 2012: 35), lo que yo entiendo que quiere decir aquí que no lo es a la manera en que ellos lo son, aferrados al Árbol Abuelo, incluidos dentro de su linaje, pero a su vez devastados por éste. Diego, Alonso y Gabriel, me parece, son al poeta de Las sienes del asno de oro, lo que Rosalía, Efigenia y Soledad son a Lucila, nombre de nacimiento de la autora de "Todas íbamos a ser reinas": condenados por lo que se les dijo que iban a ser, que tenían que ser, y que ellos mismos cantaban embriagados, aquello que nunca llegaron a ser; solo Lucila y Alejandro tuvieron "otro reino", más terrible quizá, "en las lunas de la locura" y "su manto en la tempestad". A diferencia del linaje masculino del abuelo, el sujeto es parte de una "casquivana descendencia", el "pan de los viñedos" (Godoy 2012: 21), algo, alguien que, además de entregarse como alimento, como ofrenda, en sacrificio, se presenta traslapado, desplazado, injertado, sin correspondencia ni concordancia. El mulo mestizo lezamiano es aquí el asno vernáculo, el de las sienes

$8 \quad$ Escribe Patricio Marchant en "El árbol como madre arcaica en la poesía de Gabriela Mistral" (Marchant 2000: 121): "En esta poesía la ausencia o la presencia de un Dios se demuestra -bastante heideggerianamente, pero antes de Heidegger, por supuesto- por la capacidad de un Dios de determinar un modo de existencia humano. Tres nombres de dioses se nombran en estos poemas. Primero, el Dios de David ("Aquel tremendo y fuerte señor"), Dios que no existe ahora, en este tiempo, pero que existió antes, cuando existían hombres que medían su existencia por su nombre (y Dios que fue presente para la hablante en su juventud). El segundo Dios que se nombra es el Dios triste, el Dios Padre de los cristianos; Dios inmenso por la inmensa cantidad de hombres que se determinen por él, existente ahora, pero ahora implícitamente también, siempre, Dios ontológicamente triste, débil, herido, sin aliento y, defecto capital, Dios sin canto, es decir, Dios que no es origen del canto. Tercero, finalmente, en "La cruz de Bistolfi", el nombre de Dios oculto, la Cruz".

9 "Todas íbamos a ser reinas", uno de los poemas más importantes de Tala de Gabriela Mistral (Mistral 1958: 520-3), donde dice: "Y Lucila, que hablaba a río,/ a montaña y cañaveral,/ en las lunas de la locura/ recibió reino de verdad.// En las nubes contó diez hijos/ y en los salares su reinar,/ en los ríos ha visto esposos/ y su manto en la tempestad". 
de oro: como el cisne modernista, áureo, mítico y espiritual, pero también doméstico, nativo, vernáculo, criollo si se quiere -a la manera del barroco americano-, carnal y sexuado $^{10}$. El asno de las sienes de oro es algo, alguien, que no se da por sentado, que no termina de entregarse, esa imago elusiva y además discordante -"la tardanza de la imagen" como dice el autor en otro poema (Godoy 2012: 31)-, pero también algo, alguien, que no demora en hacerse presente, que no deja incómodamente de estar ahí, un lascivo y hambriento convidado de piedra, ese "néctar gitano o moro (que) a comer se me sentaba" (Godoy 2012: 9), que se le sentaba al poeta a comer -sigo la expresión hecha- como quien se echa a llorar o a morir.

\section{BIBLIOGRAFÍA}

Anwandter, Andrés. Especies intencionales. Santiago: Quid, 2001.

Biblia de Ferrara. Edición y prólogo de Moshe Lazar. Madrid: Fundación José Antonio de Castro, (2 ed., 2004).

Girondo, Oliverio. Obra completa. Edición crítica. Raúl Antelo, coordinador; $1^{\text {a }}$ edición, Madrid; Barcelona; La Habana; Lisboa; París; México; Buenos Aires; Sao Paulo; Lima; Guatemala; San José; Caracas: ALLCA XX, 1999.

Godoy, Alejandro. Las sienes del asno de oro. Santiago, 2012. www.librosdeautor.cl.

Huidobro, Vicente. Obra poética. Edición crítica. Cedomil Goic, coordinador; $1^{\text {a }}$ edición,

Madrid; Barcelona; La Habana; Lisboa; París; México; Buenos Aires; Sao Paulo; Lima;

Guatemala; San José; Caracas, ALLCA XX, 2003.

Lezama Lima, José. Poesía completa. La Habana: Editorial Letras Cubanas, 1985.

Marchant, Patricio. Sobre árboles y madres. Santiago: Ediciones Gato Murr, 1984.

Escritura y temblor. Edición de Pablo Oyarzún y Willy Thayer. Santiago: Editorial Cuarto Propio, 2000.

Mistral, Gabriela. Poesías completas. Edición de Margaret Bates. Madrid: Ediciones Aguilar, 1958.

10 Me refiero al poema "Rapsodia para el mulo" de José Lezama Lima, de su libro La fijeza (Lezama 1985: 163-7), uno de los grandes textos meta-irónicos sobre la condición mestiza de la cultura americana. 